\title{
Geographic distribution of an open access e-journal
}

\author{
Teresa S. Welsh* and Stacy Creel \\ University of Southern Mississippi, Hattiesburg, MS, USA
}

\begin{abstract}
Spatial analysis of usage data for a new open-access library and information science e-journal indicates that within the US the geographic distribution of page views is similar to the geographic distribution of the sponsoring program's alumni locations. Outside the US, the geographic distribution of page views was greatest in Europe, followed by Asia, Africa and South America. The top two most frequently downloaded articles are both related to classic children's literature, a content analysis of Cinderella storybooks in the de Grummond Collection and a collection analysis of Little Red Riding Hood in the de Grummond Collection.
\end{abstract}

Keywords: Spatial analysis, open-access e-journal, e-journal, library and information science journal, LIS journal

\section{Introduction}

Open access was defined in the 2002 Bethesda Statement and in the 2003 Berlin Declaration as "barrier-free access to all academic work on the internet, license to copy, distribute, transmit and display the work publicly and to make and to distribute any derivative works to proper attribution of authorship, and deposit the work and any supplemental material in at least one online repository for open access and long term archiving" [14].

According to Xia, although spatial characteristics of open-access have been explored in previous studies, such as the 2009 study by Evans and Reimer, "few have attempted to investigate issues beyond the variation of OA citation behavior" and "few studies have taken a transnational view to analyze OA geography at the global level" [21]. This study analyzes the geographic distribution of usage data of a new LIS open-access e-journal.

\section{Background: SLIS Connecting e-journal}

Of fifty-eight library and information science programs currently accredited by the American Library Association (ALA) in the United States and Canada, the University of Southern Mississippi's School of Library and Information Science (SLIS) is one of only twenty offered completely online. Part of the accreditation process includes maintaining contact and communication with students and alumni.

\footnotetext{
${ }^{*}$ Corresponding author: Dr. Teresa S. Welsh, Associate Professor, University of Southern Mississippi, 118 College Drive \#5146, Hattiesburg, MS 39402, USA. E-mail: teresa.welsh@usm.edu. 
This can be a difficult task to accomplish when faculty may never meet students in person and students are located all over the state, the United States, and the world. Fortunately, re-accreditation coincided with the university library's introduction of the Aquila digital repository (http://aquila.usm.edu/) hosted through Digital Commons.

Once Aquila was in place, Digital Commons software made it easy to develop and produce an open access journal called SLIS Connecting. The purpose of the online publication is "to share news, information and research with future students, current students, alumni, faculty, and the general population through selected faculty publications, invited student publications, refereed publications, and through regular columns" [17]. The first issue was electronically published in February 2012 and the second in October 2012. The third issue was published in February 2013 and contains the first paper submitted from an author not affiliated with SLIS. SLIS Connecting is currently indexed in Google Search and in Google Scholar.

\subsection{Features of digital commons by bepress}

Bepress, originally Berkeley Electronic Press, was founded in 1999 because "academic journals were plagued by slow turnaround times, limited access, and unreasonable prices" [2]. One of the first projects of bepress was to develop a streamlined online editorial management system that supports the peerreview process. The system allows a quick turnaround time for submitting authors, access for reviewers, and commitment to lower prices for libraries [2].

The next major project was Digital Commons for institutional repositories. In addition to allowing access to scholarship and information, it supports "faculty in creating and editing sustainable scholarly journals, as well as a variety of other publishing initiatives like e-only press imprints, conference proceedings, student research, and more" [2]. A license with Digital Commons entitles the institution to setup, training, support - including unlimited technical support, documentation, upgrades, and hosting. Institutions are provided five free journals, which includes setup design. "Digital Commons comes uniquely equipped with EdiKit ${ }^{\mathrm{TM}}$, a professional-grade peer-review/editorial management system. EdiKit extends professional publishing services to faculty, students, and other scholars" [2]. Digital Commons also supports social networking features with sharing through Facebook, Twitter, LinkedIn, StumbleUpon, Pinterest, RSS and much more.

\section{Literature}

\subsection{Open access}

"The transformation from print to digital media for scientific communication, driven in part by the growth of the Internet and the tremendous explosion in the amount of information now available to everybody, is creating fundamental changes in institutions such as publishers, libraries, and universities that primarily exist for the creation, management, and distribution of information and knowledge" [5]. This transformation has had an important impact on the academic library in that traditional duties are changing, including the loss and replacement of print journals with digital copies found in archiving services and entirely online journals. The library is seen as more than a physical location; it has become an "online gateway" [5]. The impact of electronic publishing has not been limited to the academic 
library, but has impacted academia as a whole especially in the case of open access publishing. In open access publishing, the emphasis is on "the value of free dissemination of scholarly knowledge" [11]. Open access embraces the idea of making scholarly and professional information and knowledge readily available for free and is a growing alternative to fee-based traditional journal subscriptions [20].

"Institutions have turned themselves into major publishers in their own right ..." [4]. It is necessary to consider how the use of the web has changed the way academics share, promote, and locate information [4]. In the use of electronic journals by academics, convenience, including free access, is important [15]. These same institutions have begun a new type of institutional repository in which the work of faculty is collected and disseminated. These digital repositories ingest, store, and provide some level of content management for the digital materials [1].

The Association of Research Libraries maintains that open access research is a critical driver of scientific innovation and productivity. "It increases citations and follow-on research, promotes diversity in follow-on research, increases the pursuit of new research pathways, encourages faster application of research" [10].

\subsection{Spatial analysis}

"The internal and external scholarly communication of a discipline can be understood by mapping its published literature" [9]. In most cases, this is accomplished by assessing the journal content, readership, citation, or distribution [13]. Recently, studies have emerged addressing the geographic distribution of citations of scholarly materials found in open access journals and the geographic growth of open access journals themselves [6,21]. A geographic information system or GIS is a computer software application "capable of assembling, storing, manipulating and displaying geographically referenced information (that is data identified according to their locations)" [18]. Tomlinson was the first to use the term "geographic information system" in the early 1960s to refer to computer software that used geospatial data for analysis $[3,16,19]$. GIS is a powerful tool that can be used for visualizing and analyzing geographic distribution patterns, such as usage patterns [12].

\section{Methodology}

Bepress software records the geographic location of page-views and file downloads of articles indexed in Digital Commons, which allows for spatial analysis of e-journal usage data. The focus of the study was to determine the geographical distribution for an open access LIS journal in the United States and internationally. The following research questions were addressed:

- How many page views have there been for SLIS Connecting and what was the geographic distribution within the US and abroad?

- How long on average were the page views and did they differ by US and abroad?

- What is the pattern of page views over time?

- How many items were downloaded and which items were downloaded most?

Information was gathered from three resources to address the research questions. First, bepress offers usage reports, which supply hits, full-text downloads, and referral statistics that can be emailed as a Microsoft Excel file upon request. Second, bepress sends out two types of email usage updates - monthly usage reports for the journal and author dashboard reports (Fig. 1), which are specific to the authors. These emails may also contain information about the journal's standing among like-themed journals 


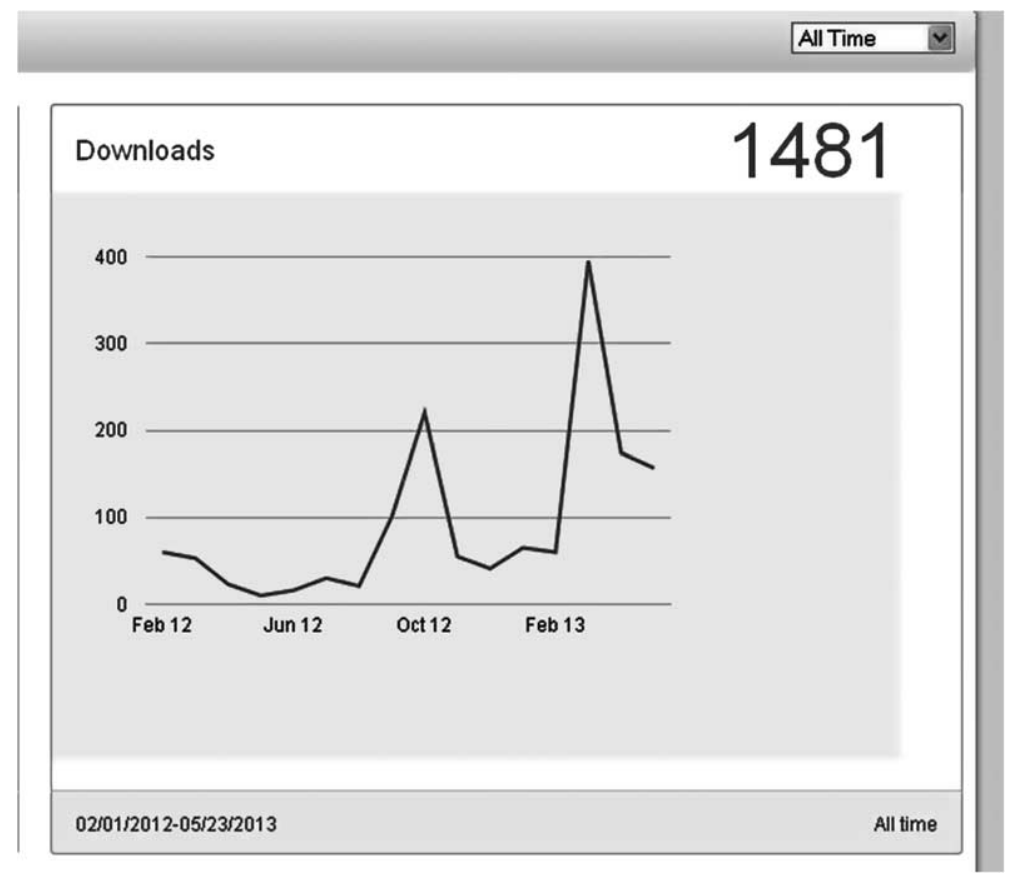

Fig. 1. Author dashboard example.

hosted in the Digital Commons Network. For example, in April SLIS Connecting was one of the "most popular" of 355 works in the Archival Science Commons.

The author dashboard report provides information on search queries, downloads, institutions, and referrers. The final source of information was Google Analytics (Fig. 2). Google Analytics supplies information on page-views, unique page-views, average time spent on a page, bounce rate, percent exit and location of views.

\section{Results}

The first question - how many page views have there been for SLIS Connecting and what was the geographic distribution within the US and abroad? - can be answered through Google Analytics. The first issue contained four regular columns, three articles from faculty, and three scholarly student papers. The second issue contained four regular columns and three scholarly student papers, and the third issue, four regular columns, a faculty article, two reports, and three scholarly student papers, one of which was from Iran. From the first issue of SLIS Connecting in February 2012 through March 2013, there were 7,012 page views.

Most, 5852 (83\%), were from US (Fig. 3). The US spatial distribution pattern is similar to the pattern of SLIS alumni locations for public and school libraries (Fig. 4) as well as the pattern for alumni in academic and special libraries: greatest in the southeast, then northeast, southwest and northwest.

The extent of international distribution was unexpected (Fig. 5). Of the 1,160 page views from 107 international cities in 85 countries, Iran had the greatest number, 220 (19\%); then Canada, $124(11 \%)$; Nigeria $108(09 \%)$, India 84 (07\%), United Kingdom 56 (05\%); Brazil, 43 (04\%), and Australia 32 $(03 \%)$. By region, the spatial distribution pattern of page views was greatest in Europe, followed by 


\section{Gooḡle Analytics}

http://aquila.usm.edu - http://aquila.usm.edu aquila.usm.edu [DEFAULT]

\section{Content Drilldown}

Feb 1, 2012 - Mar 18, 2013

\section{ALL 》 PAGE PATH LEVEL 1:/slisconnecting/}

$\checkmark \%$ of pageviews: $11.84 \%$

Explorer

Site Usage

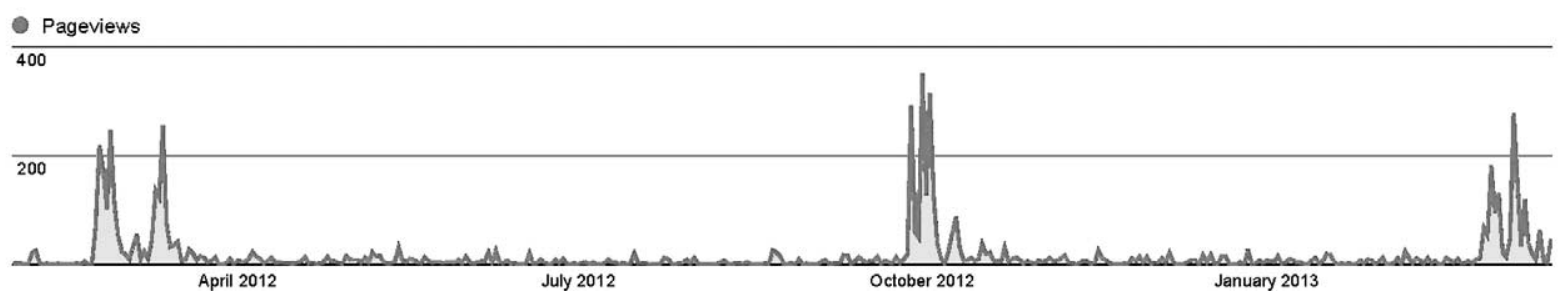

Fig. 2. Google analytics example.

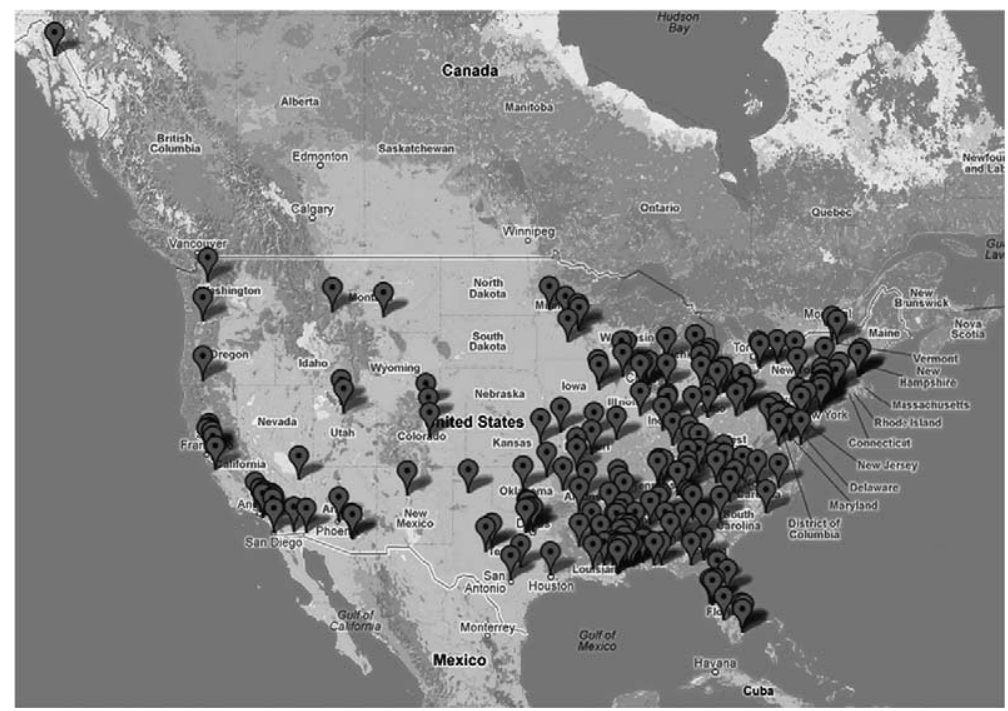

Fig. 3. Map of United States page views (Google Maps, 2013).

Asia, Africa and South America. The variety of distribution indicates that the journal was viewed internationally by a much wider audience than SLIS students and alumni.

The geographic distribution pattern by country as illustrated by shaded areas (Fig. 6) is similar to that of the distribution pattern by country of open-access journals indexed in the Directory of Open Access Journals (Fig. 7) [21].

In answering questions 2 and 3 - How long on average were the page views, did they differ by US and abroad, and what is the pattern of page views over time? - The average page-view time in the US 


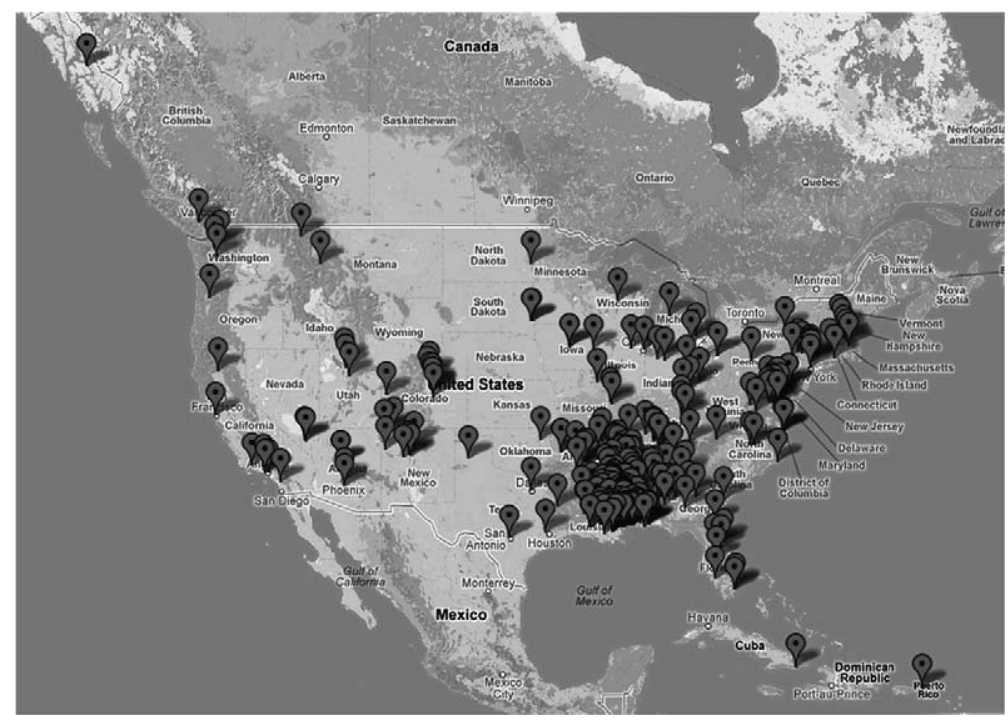

Fig. 4. Distribution pattern of SLIS public and school library alumni (Google Maps, 2013).

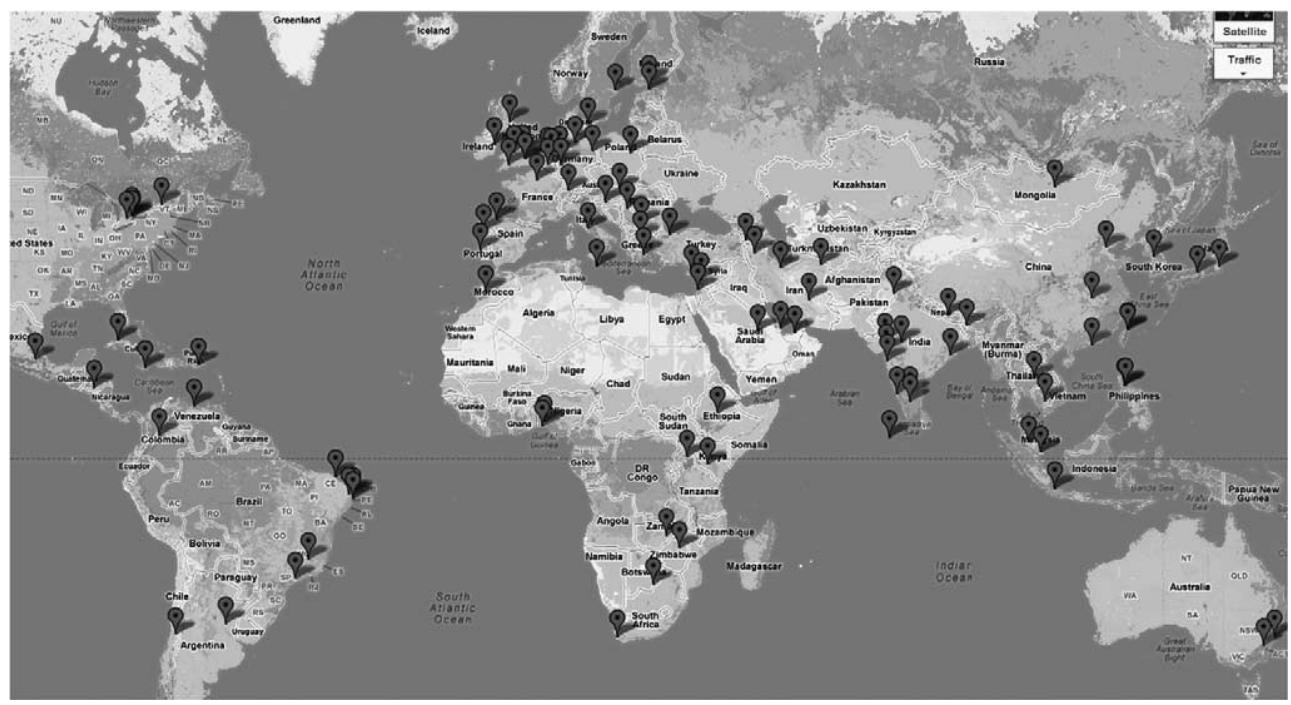

Fig. 5. International distribution pattern of page views (outside US).

was 1:14 min, which was close to the international average of 1:04. The three longest page views were from abroad. As of March 25, 2013, the three longest were in Mauritius (6:56 min), Japan (6:50) and Zimbabwe (6:14). The pattern of page views per month indicated a steady increase after each new issue, which peaked after about one month then declined until the next issue.

In regards to question 4 - How many items were downloaded and which items were downloaded most? - there were 6,048 full-text downloads. Items most downloaded were Issue 1: content analysis article (1,939), entire issue (431), library history article (309), IMLS scholarship report (161), and from Issue 2: a collection analysis article $(1,122)$, and entire issue (199). By far, the most popular downloads were "A Content Analysis of Cinderella Illustrated Storybooks Housed in the de Grummond Collection" 


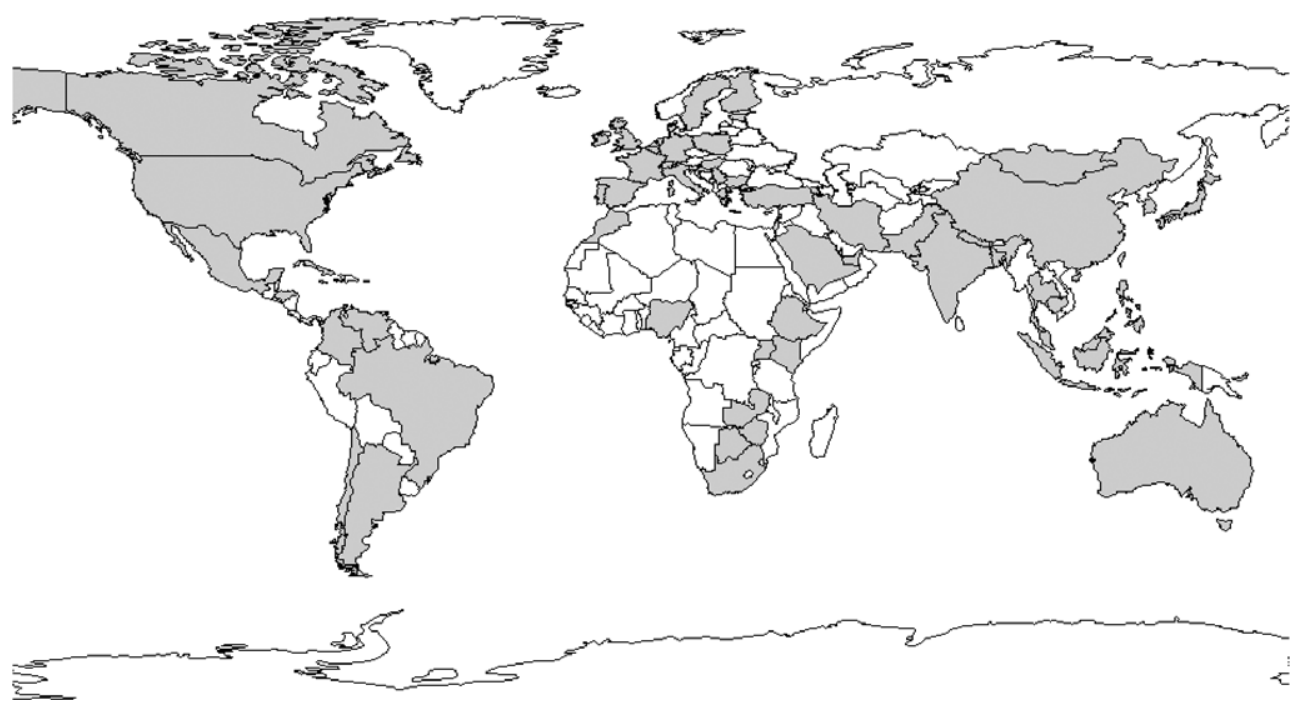

Fig. 6. Geographic distribution pattern of journal page views by country (shaded areas).

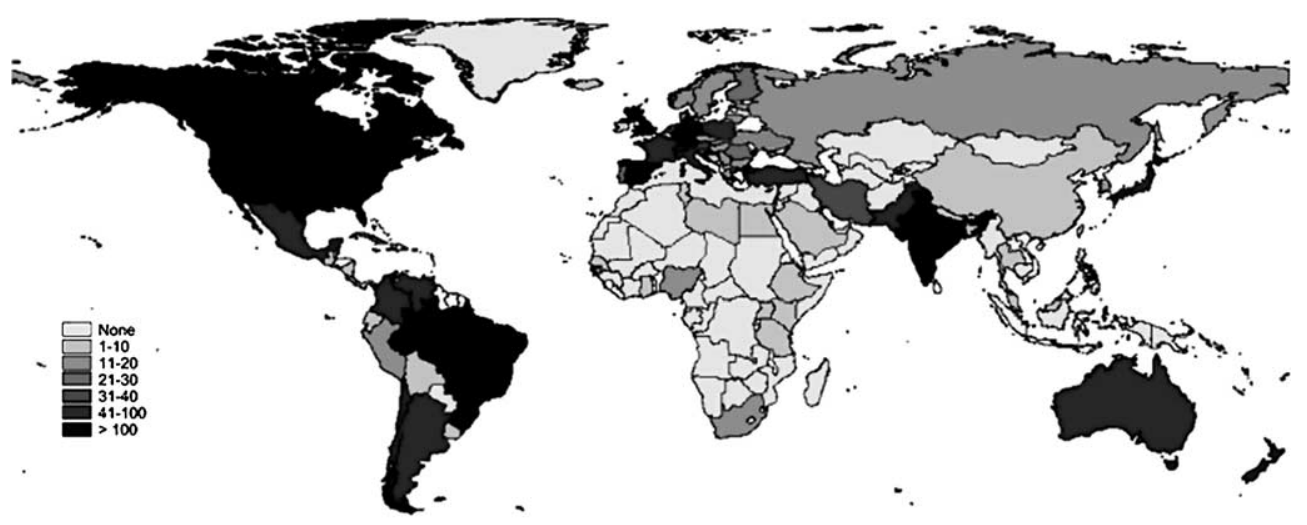

Source: http://www.doaj.org

Fig. 7. Geographic distribution of open access journal publication by country [21].

(32\%) by Kimberly Smith, published in Issue 1, followed by "An Analysis of Little Red Riding Hood Storybooks in the de Grummond Collection" (19\%) by Cheryl Pittman in Issue 2.

\section{Discussion and conclusion}

So what does the geographical distribution for the open access LIS journal look like in the United States and abroad? While the patterns in the United States align more closely to SLIS alumni distribution, the international pattern is much more diverse. There are several possible reasons for the unexpected international reach. First, SLIS Connecting is indexed in Google and Google Scholar so a search of relevant terms often results in a journal item in the first 10 hits - for example, searching Mississippi Libraries Minorities returns a SLIS Connecting article as choice one and two. Additionally, the physical location of the digital repository or open access journal is not a factor in who can access the material 
via the web and publication and acceptance of open-access journals in other countries may be another reason for SLIS Connecting's success abroad [21].

Second when a new issue is published, it is advertised on multiple listservs including jESSE and IFLA, both of which have an international reach. "As of 10 February 2005, the jESSE listserv included over 1200 members, representing 100\% of ALA-accredited schools of LIS and 24 countries. These countries include Australia, Brazil, Canada, Denmark, Egypt, Estonia, Germany, Great Britain, Greece, Hungary, Ireland, Israel, Japan, Malaysia, the Netherlands, New Zealand, Norway, Portugal, Singapore, South Africa, Spain, Taiwan, Thailand - and the US" [8]. The International Federation of Library Associations and Institutions (IFLA) is "the leading international body representing the interests of library and information services and their users. It is the global voice of the library and information profession" [7]. The IFLA listserv reaches almost 4000 subscribers worldwide. This advertisement on appropriate listservs along with the use of social media - the third potential factor - may be another factor of the international success of the journal.

In addition to posting announcements on the Facebook page for the School of Library and Information Science, both editors post updates about the journal through their personal social media accounts. The co-editors attend national and international conferences, and they are linked to more than 900 librarians, students, and academics via Facebook and to more than 5,000 librarians, LIS students, and academics as well as 47 LIS-related groups through LinkedIn. Many of these contacts are international.

Since there is currently not a way to definitely attribute the international response to any of these factors, there are future plans to add a short survey on the journal homepage to investigate how people are finding the journal and articles. It is also important to note that while some of the articles published are specific to Mississippi, others have broad appeal. The two most highly viewed articles are about fairy tales, an important topic in multiple fields, cultures, and mediums.

An idea that started as a way to contact and communicate with alumni has grown in a short time to an open access journal with international distribution. This initial research will be continued as a longitudinal study to track the geographic distribution of the journal as it changes over time.

\section{References}

[1] American Library Association, Repository applications, Library Technology Reports (February/March 2008), pp. $26-32$.

[2] bepress.com [Homepage on the Internet], bepress, Berkeley, CA, available at: http://www.bepress.com/; cited 3 January 2013.

[3] B.W. Bishop and L.H. Mandel, Utilizing geographic information systems (GIS) in library research, Library Hi Tech 28 (2010), 536-547.

[4] M. Calise, R. de Rosa and X.F. Marin, Electronic publishing, knowledge sharing and open access: A new environment for political science, European Political Science 9 (2010), S50-S60.

[5] L.A. Davidson, The end of print: Digitization and its consequence - revolutionary changes in scholarly and social communication in scientific research, International Journal of Toxicology 24 (2005), 25-34.

[6] J.A. Evans and J. Reimer, Open access and global participation in science, Science 323(5917) (2009), 1025.

[7] International Federation of Library Associations and Institutions [Homepage on the Internet], The Hague, The Netherlands, available at: http://www.ifla.org/; cited 18 March 2013.

[8] jesse.html [Homepage on the Internet], Dr. Gretchen Whitney, School of Information Sciences, University of TennesseeKnoxville, TN 37996, available at: http://web.utk.edu/ gwhitney/jesse.html; cited 18 March 2013.

[9] Z. Liu and C. Wang, Mapping interdisciplinarity in demography: A journal network analysis, Journal of Information Science 31(4) (2005), 308-316.

[10] C.B. Lowry, The "Open Movement" in research scholarship - What is it and what does it mean?, Information Services \& Use 32 (2012), 149-153.

[11] C. May, The end of scholarly publishing as we know it?: Open access journals and other forms of open distribution of information, in: Political Economy of Transnational Information Flows, International Studies Association Annual Convention, Honolulu, March 5, 2005, Presentation SA13. 
[12] M. Michalec and T.S. Welsh, Quantity and authorship of GIS articles in library and information science literature, 1190-2005, Science \& Technology Libraries 27 (2007), 65-77.

[13] J.M. Reitz, Bibliometrics, Online Dictionary for Library and Information Science (2013), available at: http://www. abc-clio.com/ODLIS; cited 10 June 2013.

[14] A.K. Richter, Open access - A never ending story?, Information Services \& Use 28 (2008), 97-103.

[15] C. Tenopir and R.E. Wolverton, Conference report: Discovering the magic: Faculty and student use of electronic journals, The Serials Librarian 49(3) (2005), 159-164.

[16] R. Tomlinson, The Canadian geographic information system, in: The History of Geographic Information Systems: Perspectives from the Pioneer, T.W. Foresman, ed., Prentice-Hall, 1998, pp. 21-32.

[17] University of Southern Mississippi, SLIS Connecting, available at: http://aquila.usm.edu/slisconnecting/.

[18] US Geological Survey, Global geographic information systems, available at: http://webgis.wr.usgs.gov/globalgis/; cited 12 June 2013.

[19] T. Wade, S. Sommer, A to Z GIS: An Illustrated Dictionary of Geographic Information Systems, ESRI Press, 2006.

[20] J. Willis, Scholarly knowledge development and dissemination in an international context: Approaches and tools for higher education, Computers in the Schools 27(3,4) (2010), 155-199.

[21] J. Xia, Diffusionism and open access, Journal of Documentation 68 (2012), 72-99. 